\title{
THE USE OF ENGLISH AS LINGUA FRANCA IN CROSS-CULTURAL CLASSES: A CASE STUDY IN DESIGN AND ENGINEERING EDUCATION
}

\author{
Silvia FERRARIS and Francesca MATTIOLI \\ Politecnico di Milano, Italy
}

\begin{abstract}
The increasing mobility of students is shaping a new higher education landscape, which is characterized by a higher number of cross-cultural courses and, consequently, a relevant ratio of international classes. In these learning environments, students are exposed to cultural diversity and, if supported in this sense, they learn to have an open-minded attitude to other cultures. This approach is aimed at developing a curriculum better suited for the growing global job market.

On the other hand, since students are not anymore native speakers, the language used in the learning environment becomes a relevant issue. The use of English as lingua franca is often the choice to address the linguistic diversity, both in English speaking and non-English speaking countries.

However, learning and teaching in English is not an easy task for non-native speakers. Due to language gaps, some contents are sometimes not fully communicated or even missed.

In this regard, the case study of the Master of Science course in Design and Engineering of Politecnico di Milano is presented. The course went through a five-year internationalization process, which led to a gradual transition from Italian to English. This paper proposes to point out the advantages and disadvantages of the transition from the native language to English in Design and Engineering higher education courses. Following the assumption that the use of English as lingua franca is the easiest way to implement cross-cultural education curricula, the authors look for some improvements that could be done to enhance the communication process between all the stakeholders.
\end{abstract}

Keywords: Cross-cultural classes, international curricula, lingua franca

\section{INTRODUCTION}

\subsection{The overall perspective}

This paper reflects on higher education programmes that are offered in English to multicultural classes in countries where English is not the first language, drawing on the experience we have in of Politecnico di Milano.

The choice at the heart of these programmes is mainly driven by the idea that a multicultural class will stimulate the students, local and international, to have a better understating of other cultures and possibly develop an open-minded attitude toward multicultural environments. This approach is thought to support the development of a curriculum better suited for the growing global job market. This choice is also consistent with the aim of the EU Council Recommendation on a comprehensive approach to the teaching and learning of languages that claims: "Language skills are at the heart of the ambitious vision to create a European Education Area. Being able to speak foreign languages is not only a skill needed for studying abroad, but also on increasingly international job markets. Learning languages enables people to both discover foreign cultures and to broaden their perspectives." [1]

Many institutions promote the developing of international learning environments as a matter of ethical value [2]. In this perspective, the idea of interacting in multicultural classes, learning to be open-minded and express themselves in a second language are all soft skills that respond to the future challenges in higher education, also in technical studies such as design and engineering education. 


\subsection{A local case study}

This paper focuses on the case study of the Master of Science in Design and Engineering programme held at of Politecnico di Milano. From 2012, the course went through an internationalization process, which led to the gradual transition of the official language from Italian to English. Following this process, also the students' origin has changed so that the classes are currently more international. Both the institution and the students' representatives claim that this was a positive step for the degree course. Nevertheless, there has not been any reflection on this specific topic so far, even though a large amount of data is collected every year to evaluate the performances of teachers and students. Thus, the authors propose an evaluation of the process with a mixed approach, interplaying quantitative institutional data and qualitative data collected through a questionnaire.

The intention of the authors is to assess the relationship between the way students are evaluated through their study path in the Master and to highlight possible connections with their knowledge of English language. The discussion presents trends that emerged from this analysis and from the comparison of qualitative and quantitative data.

\section{THE INTERNATIONALIZATION PROCESS}

The process of internationalization undertaken within the Design and Engineering course is part of an extensive action promoted by of Politecnico di Milano and addressed to all the postgraduate programmes (i.e. in design, in engineering and in architecture). Until the academic year 2011/12 the Master accepted up to 60 students and was exclusively taught in Italian. At that time, only 10 places were reserved for international students, but that number was seldomly reached. Starting from 2012 the programme begun to offer the option to take some of the courses in English. Simultaneously, the number of places for students was raised to 100 , of which 20 were reserved to international students. Yet, the number of enrolled international students did not fill the available places.

In the academic year 2014/15 the internationalization process was completed, meaning that any student could graduate by taking courses taught exclusively in English. That year it was also decided to require a higher level of English for the admission and to change the ratio of reserved places for Italian and international students (from 80/20 to 65/35) to guarantee a more international class.

The number of enrolled Italian students fell in 2015/16 probably due to the higher level of English required. The year after the number of Italian students enrolled increased again. Meanwhile, the number of international students noticeably raised. In the academic year 2017/18 the total number of available places decreased to 90 and ratio of places reserved to Italian and International students changed again (from 65/35 to 55/35). Since then the available numbers are filled, the study path is fully in English and international as planned.

To complete the description of the programme, we must highlight that the Faculty is composed entirely of Italian teachers who speak English as a second language. Moreover, the teachers are either professors who belong to Name of Institution or invited lecturers that have graduated from the same Master programme or professionals with a remarkable experience in the field.

\section{THE CASE STUDY}

\subsection{The quantitative analysis}

Every year the Faculty of the M.Sc. evaluates the performance of the programme, based on several parameters and data provided by Politecnico di Milano. Some of these are quantitative data about students' performances through their whole study path. No specific information is provided regarding the use of English language, nor to the integration of students within the multicultural classes. To address the impact of using English as a lingua franca, we interpreted some of this quantitative data that appeared to be relevant to this end. This assessment is therefore based on indirect data, but still useful to have a preliminary overview on the matter.

First, we analysed the students' performance in relation to their origins. Our intent was to trace students coming from English-speaking countries to see if they had been advantaged by that. In the further analysis we consider that the "origins" regards the place where the student graduated before attending the Master (e.g. a Spanish student graduated in England, would be considered as "coming from UK"). The country is represented if at least three students came from there in that period, otherwise they are summed in "all other countries". In Table 1 the average grade (from 2014/15 to 2017/18) of students at the second year are displayed by origins (the "average grade" is the sum of all marks taken since the beginning of the M.Sc. divided by the total number of courses). The data disconfirmed the hypothesis 
that students coming from English-speaking countries were advantaged; indeed, there is no direct relation between "English-speaking country of origin" and "performance". For instance, the value of the average grade is equal for USA, Colombia and Serbia and minor for India (considered as a nativeEnglish Country) than Mexico.

Table 1. The performance of international students

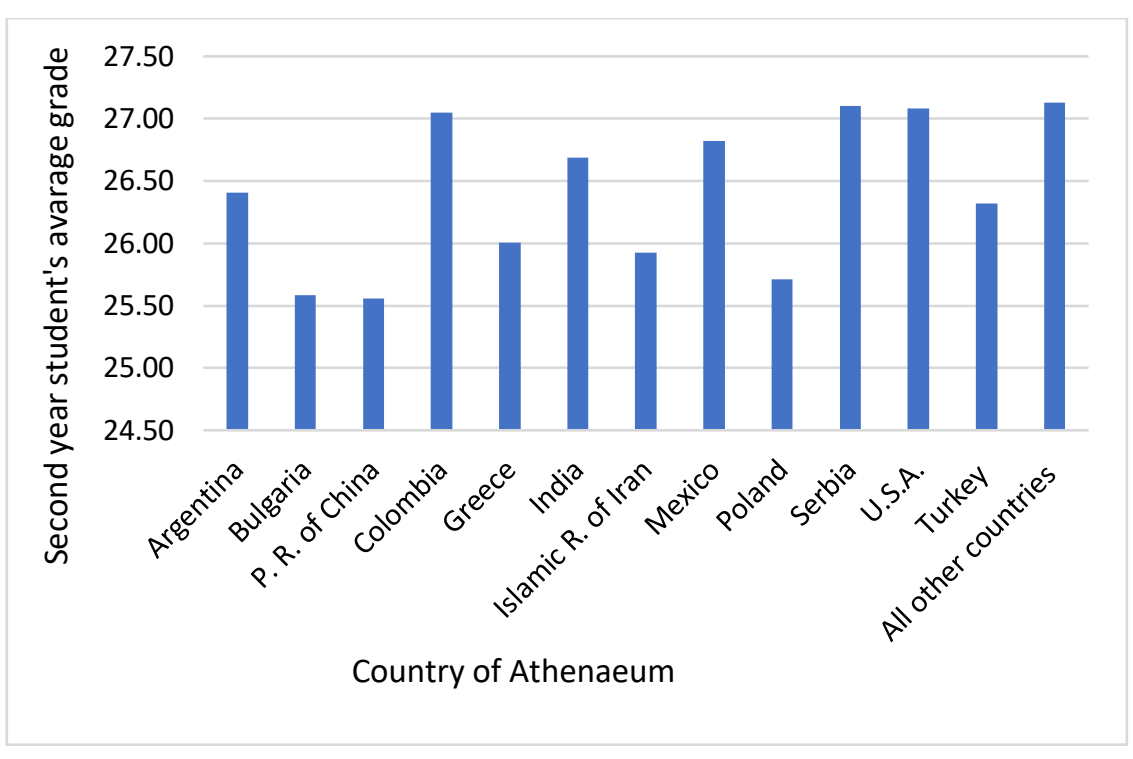

Secondly, we analysed the performance of the best graduates comparing them by origins (see Table 2). We observe that none of the five international students who graduated with the best grade (110 with honours) comes from an English-speaking country. This data disconfirms our initial hypothesis as well. A more striking hypothesis emerged from the interpretation of this data; students coming from bachelor programmes at Politecnico di Milano are the one graduating with the highest grades. Indeed, the number of best graduates from the home institution these students is four times higher than number of students graduating with the best grade coming other Italian institution and ten times higher than the one coming from international institutions. It seems quite evident that the impact on performance is not related to the language of the country of origins but rather on the academic background. Going over the simplistic assumption "our students are better", which is surprisingly sometimes heard from the teachers "side, we try to understand more deeply what phenomenon is hidden behind these data.

Table 2. Provenance of the best graduate students

\begin{tabular}{|l|r|l|r|l|}
\hline \multicolumn{5}{|l|}{ Number of graduates with honors and provenance of Institution } \\
\hline Academic year & $\begin{array}{l}\text { Name of } \\
\text { Institution }\end{array}$ & $\begin{array}{l}\text { Other Italian } \\
\text { Institution }\end{array}$ & \multicolumn{2}{|l|}{ Other international Institution } \\
\hline $2011 / 12$ & 4 & 0 & 0 & \\
\hline $2012 / 13$ & 10 & 1 & 0 & \\
\hline $2013 / 14$ & 4 & 3 & 1 & Colombia \\
\hline $2014 / 15$ & 7 & 1 & 0 & \\
\hline $2015 / 16$ & 8 & 2 & 0 & \\
\hline $2016 / 17$ & 13 & 2 & 3 & Serbia, Poland, Israel \\
\hline $2017 / 18$ & 8 & 4 & 1 & Netherlands \\
\hline Total & 54 & 13 & 5 & \\
\hline
\end{tabular}

Thirdly, we analysed the performance of students in courses that present a different kind of teaching approach. On one hand there are the Design Studios (the first three in Table 3), which are design-based learning courses [3] where students learn design by doing it, being engaged in teams' project works to develop an industrial product with the supervision of teachers. In this case students are encouraged, but 
not obliged, to make multicultural and multidisciplinary teams. At the end, the evaluation is the same for each team member. On the other hand, there are theoretical courses which are often based on traditional receptive architectures [4], where notions and contents are provided through ex-cathedra lectures and textbooks. In this case, students work and are evaluated individually. We took three diverse examples to cover the whole spectrum of cases. "Design Thinking and Processes" and "Design and Manufacturing" are mandatory theoretical courses, the first from the design disciplinary area and the second from engineering area. The third course "Reverse modelling" is an optional theoretical course. In this analysis our hypothesis was that the impact of the use of English could be less relevant in the Design Studios, since this kind of teaching is more practice-based, and it is supported by tools other than language (e.g. drawings, models). However, from reading the data we observe that the performance of international students is always slightly lower than that of Italians, regardless of the course and the didactic approach.

Table 3. Students performance in different kind of courses

\begin{tabular}{|c|c|c|c|c|c|c|}
\hline Course & & Student & 2016/17 & $2017 / 18$ & $2018 / 19$ & Average \\
\hline \multirow{2}{*}{ Product development design studio 1} & \multirow{6}{*}{$\begin{array}{l}\text { Design } \\
\text { studios, } \\
\text { work in } \\
\text { teams }\end{array}$} & Italian & 27,69 & 26,91 & 27,53 & 27,38 \\
\hline & & International & 25,2 & 26,24 & 26,36 & 25,93 \\
\hline \multirow[t]{2}{*}{ Product development design studio 2} & & Italian & 27,4 & 27,29 & 26,67 & 27,12 \\
\hline & & International & 25,78 & 26,37 & 25,15 & 25,77 \\
\hline \multirow[t]{2}{*}{ Final project work 1} & & Italian & 28,47 & 28,63 & 28,93 & 28,68 \\
\hline & & International & 26,22 & 27,63 & 28,56 & 27,47 \\
\hline \multirow[t]{2}{*}{ Design thinking and processes } & \multirow{6}{*}{$\begin{array}{l}\text { Theoretical } \\
\text { courses, } \\
\text { individual } \\
\text { work }\end{array}$} & Italian & 27,63 & 26,93 & 26,02 & 26,86 \\
\hline & & International & 25,9 & 25,08 & 23,28 & 24,75 \\
\hline \multirow{2}{*}{ Design and manufacturing } & & Italian & 28,05 & 25,8 & 25,5 & 26,45 \\
\hline & & International & 26,38 & 25,04 & 24,75 & 25,39 \\
\hline \multirow[t]{2}{*}{ Reverse modelling } & & Italian & 28 & 26,15 & 26,13 & 26,76 \\
\hline & & International & 26,96 & 25,2 & 25,78 & 25,98 \\
\hline
\end{tabular}

The quantitative analysis of the data available does not show an evident relation of the use of English and the performance of students. What appears more relevant is the constant different performance of international students and Italians. It seems that the main difference is between students coming from bachelor programmes at Name of Institution and those coming from other Italian or international institutions. An integration issue raises from this study, which suggests that academic culture that might be the stronger barrier for students and the most relevant bias to overcome for professors.

Furthermore, these data evaluate only the performance in terms of individual grades. We are not able to assess the experience of the students and their perception of the advantages or disadvantages of being in a multicultural learning environment. For this reason, we engaged with a qualitative analysis to better understand student's perception.

\subsection{The qualitative analysis}

For the qualitative analysis we asked the students to answer to a questionnaire, designed to collect data about their experience and perception regarding the use of English in the Design and Engineering Master. We collected the responses to the questionnaire from 88 students out of 205 currently enrolled in the master.

Firstly, we asked which their First Language(s) was, and the answers showed that the 52.3\% of them speaks Italian, the $18.2 \%$ English, the 10\% Spanish, the 5.7\% Chinese and less than the $2 \%$ other languages.

Secondly, we asked the reason why they decided to enrol in a master's degree programme in English. They had the possibility to answer both checking pre-set multiple choices and writing other answers. The given multiple choice answers (and responses) were: "I wanted to attend this master, regardless of whether it is taught in English" (54.5\%), "I do not speak Italian" (35.2\%), "to improve my English" (18.2\%). Seven students also added personal answers to the question, mentioning, on one side, general quality reasons (i.e. "An English master is a much richer master and a master of global breath"), on the other, they just said to have no other choices. 
The questionnaire continued with 17 statements that students could confirm as true or discard as false, evaluating them from 1 to 5 (where 1 was "not true" and 5 was "very true") and were divided in three sections. In the first section the students were asked to reflect on the value they attributed to a master in English before attending it. The $80,2 \%$ of the students confirmed as true (graded 4 or 5) that a master in English would have "guaranteed a curriculum better suited for the growing global job market", while only $53.8 \%$ of them (graded 4 or 5 ) thought that it would have "guaranteed a curriculum better suited for their also Country of origin". The majority confirmed true $(65.9 \%$ graded 5) that they assumed that a master in English would have "guaranteed a multicultural environment, was a positive value" and that it would have "allowed to meet students from all over the World, making everybody more openminded" (59.1\% graded 5).

In the second section the students were asked to reflect on the positive and negative aspects of using English during the master. Students generally agreed with the idea that English "is a lingua franca that allows everyone to communicate" (85.2\% graded 4 and 5) and that "it allows you to create a multicultural environment shared by all" (86.4\% graded 4 and 5). On the other hand, they are more sceptical about the idea that "speaking the same language, students do not create separate monocultural groups in everyday campus' life" (50\% graded 4 and 5).

Concerning with the negative impact of using English as lingua franca, students demonstrated with their answers to have very different viewpoints. For instance, $36.3 \%$ of the students confirmed as true (graded 4 or 5) the idea that "the level of English influences the evaluation by the teachers," while $46.6 \%$ do not agree with that (graded 1 or 2).

The last section students were asked to evaluate a series of statements about final remarks about the use of English. The vast majority confirmed as true the idea that it is "essential, despite the difficulties" (88.7\% graded 4 or 5) and it "enables students to become better citizens of an increasingly globalized world" (75\% graded 4 or 5 ).

In each section and in the final part of the questionnaire we also left space for open-ended comments, which provided further insights about students' perceptions and experiences. We grouped them in some recurring topic. One is about the level of English of both teachers and students, which is perceived as a factor that in some cases has an impact both on the teaching activities and on the assessment. Some Italian-speaking students pointed out that a better learning of a complex subject requires the use of First language and thus suggest the opportunity to have all the courses both in Italian and English.

Several students positively evaluated the use of English since, using the words of one of them "it gives to the course, and to of Politecnico di Milano itself, a higher competitive weight in a worldwide scenario" and because it allows to develop a multicultural environment. To this last point it must be noticed that not everybody agreed and a student pointed out that "Italian people are with Italians, Spanish speaking people are with them, Chinese people are with Chinese so whether I speak English or not, there are less chances to get diverse and international communications". Furthermore, someone reported that Italians teachers and students tend to speak Italian among themselves and this makes the non-Italian speakers feeling discriminated or somehow excluded.

Contradictory comments are collected on the use of English in the campus, outside the class, In fact, some students regretted the fact that the use of Italian language is not much, while they would have preferred it to be part of the experience in Italy and asked for Italian courses too.

Then, some students stated that, even if the multicultural environment allowed by the use of a lingua franca guarantees the international experience they expected, they felt disappointment when cultural plurality was not taken much in account by professors and considered as an element to enhance.

"A lot of us travelled the world to be part of a community that would allow us to grow more than just in the professional aspects, the inconvenient part is that there are a lot of the teachers that don't share that way of thinking and remained to favour their language and vision" (Student's answer)

On the other hand, another student stated that:

"In a such connected and globalized world where every person of our age has the tools and possibilities to learn English outside of school, there is no need of providing courses in English even in the bachelor. The risk is that we are going to lose our identity, our language and our culture just because the world requires us to be more 'international', but we already are like this, even if we don't want to. 


\section{Personally, I think that providing the master course in English is a disadvantage for us Italians" (Student's answer)}

These two last answers, fully transcribed, provide deeper insights and more articulated reflections about the relation between language and cultural identity.

\section{Discussion}

This preliminary study on the use of English in multicultural higher education courses, based on the case study of a Design and Engineering programme, reveals some emerging relevant issue, that is worth further investigation. First, of Politecnico di Milano is organized to collect a vast amount of data on performance of its programmes, but not to investigate specifically on the use of English neither on the integration of students in the multicultural classes. The first reflection concerned with the need to investigate this phenomenon whenever English is used as lingua franca.

The case study showed that quantitative data is not enough, and it must be interplayed with qualitative information is necessary. The questionnaire designed and used in this case study is a first example in this direction.

From the analysis of both quantitative and qualitative data it was possible to find out that most students perceived as a positive value the use of English at master level. This agreement includes the idea that a multicultural environment is more stimulating at a general level, not just the educational one (e.g. to develop an open mind), and that it provides a curriculum better suited for the growing global job market. Yet, this broad "value of multiculturality" does not completely discloses its full potential. It appears that the use of English is not enough to make the class and the life on campus truly integrated. Italians being the native and majority tend to speak their First language. Also, some students sharing the same language might group up by themselves. We wonder if this lack of integration might be at the basis of the lower performances of international students. As regards for students' performance, though, we noticed that the academic origin is more important than the country of origin, since also the Italians coming from other institutions have a lower performance. This led to the acknowledge that the idea of "multiculturality" must necessarily consider student's culture in a holistic way, not just taking in account their country of origin nor their disciplinary background (i.e. engineers and designers).

The use of English seems not to advantage any group of students, while the knowledge of Italian seems to make life easier in the daily life on campus.

\section{CONCLUSIONS}

Eventually, the choice of adopting English as a lingua franca is an ideological issue that is largely debated at the institutional and national level. The supporters of the use of English point out that it enables the institution and the single programmes to reach an international level, which allows the student to live in a rich multicultural environment and to develop a better curriculum. The counterpart points out that the use of a second language diminishes the quality of teaching, decreases the diffusion of the local (i.e. Italian) culture and is not a real advantage for the local students. With their responses the students allow for further consideration both positions, confirming that the use of English is necessary but somehow controversial. Despite the downward, they vastly agree that the use of English is essential, providing a very important confirmation for the internationalization process conducted so far. Further research should assess and gain a deeper understanding of the negative consequences registered through this preliminary data collection, to be able to act and to make a change, avoiding them.

\section{REFERENCES}

[1] https://ec.europa.eu/education/education-in-the-eu/council-recommendation-improving-teachingand-learning-languages_en

[2] Politecnico di Milano website

[3] Gómez Puente, S. M. Design-based learning: exploring an educational approach for engineering education, 2014 (Eindhoven University of Technology).

[4] Bonaiuti, G. Le strategie didattiche, 2014 (Carocci). 